\title{
RATES OF RETURN TO EDUCATION: DOES THE CONVENTIONAL PATTERN PREVAIL IN SUB-SAHARAN AFRICA?
}

\section{PAUL BENNELL}

Fellow, Institute of Development Studies at the University of Sussex, Brighton BN1 9RE, U.K.

Telephone: Home-01273-503259 


\section{SUMMARY}

In his most recent review of rates of return to education (RORE), George Psacharopoulos reaffirms that the conventional pattern of continent-wide aggregate social and private ROREs continues to prevail among both developed and developing countries. In particular, "primary education continues to exhibit the highest social profitability in the world regions" (Psacharopoulos, 1994). However, a detailed examination of individual RORE studies undertaken in Sub-Saharan African countries reveals pervasive theoretical and empirical shortcomings which seriously undermine the credibility of aggregate RORE estimates for the continent as a whole. 


\section{INTRODUCTION}

At regular intervals during the last twenty years, George Psacharopoulos (GP) has produced comprehensive reviews of rates of return to education (RORE) in developed and developing countries $(1973 ; 1980 ; 1985 ; 1993)$. The main findings of these reviews are constantly cited in the economics of education literature and in government and aid donor documents concerned with education priorities and policies in developing countries. As a senior economist at the World Bank, GP has been especially influential in shaping the Bank's own education and vocational training policies.

For each of the four reviews, GP has impressively marshalled all available RORE country studies, vetted their data and methodologies, and calculated private and social aggregate ROREs for each of the main geographical regions of the world (see Table 1). On the basis of these data, GP has argued persuasively that the following uniform pattern of ROREs is clearly discernible throughout the world:

1.ROREs for all levels of education generally exceed the aggregate social opportunity cost of capital;

2.ROREs in developing countries (and especially Africa) are higher than in the advanced market economies;

3.The private and social ROREs are highest for primary education, followed by secondary education; 
4.Private ROREs to higher education are usually considerably higher than the corresponding social ROREs;

5.The pattern of ROREs remains stable as countries develop with only relatively minor declines in ROREs.

This allegedly universal RORE pattern played a key role in shaping and underpinning World Bank lending policies and practices for its education and training sector work in SSA during the 1980s. In particular, three of the Bank's most important education policy recommendations follow logically from GP's patterns. First, all education at whatever level is a relatively attractive investment not only for individuals but also governments. Second, with certain caveats, "in most developing countries primary education should receive the highest investment priority, followed by secondary education" (World Bank, 1986:p.9). And third, government subsidisation of higher, and to a lesser extent, secondary education is excessive given the large differentials that exist between private and social ROREs. To remedy this misallocation of resources students should be made to contribute significantly more to the costs of their own education.

In the latest review, GP comments that while social and private ROREs have tended to decline as a country's per capita income increases, all levels of education remain relatively attractive vis a vis other types of public investment and that "primary education continues to exhibit the highest social profitability in the world regions" (1993 , p.7).

Reliance on market-based indicators such as ROREs in achieving allocative efficiency is of course entirely consistent with the neo-liberal development paradigm that has so strongly influenced World Bank lending policies. More substantively, the strong emphasis given to both the provision of primary education (in order to improve productivity and the overall 
quality of life among the poor concentrated in the subsistence agricultural and informal sectors) and increased cost recovery is directly supportive (in theory, at least) of World Bank inspired and/or designed structural adjustment and poverty alleviation programmes.

While numerous criticisms have been made concerning the use of ROREs in guiding resource allocation decisions for publicly funded education and training provision (see, for example, Schultz (1988); Klees (1989); Fields (1980) and Behrman and Birdsall), GP's global and continent-wide aggregate RORE estimates have not been subject to any systematic scrutiny. It would appear, therefore, that for all but a few, mainly academic detractors, the persuasiveness of GP's RORE propositions have, in effect, become the received wisdom. This is particularly apparent among the major aid donors operating in Africa where there has been a decisive shift of emphasis away from funding higher and technical and vocational education projects towards primary and basic education. Not surprisingly, universities and other higher education institutions in SSA have been critical of the policy recommendations that have been drawn from the now conventional pattern ROREs, particularly the need for much higher levels of cost recovery. But, since the early 1990s, the overarching objective of "Education For All" has increasingly dominated government education policies and policy-related discourse in SSA. The much higher social rates of return to primary education reported by GP and others has provided powerful support for this new emphasis on basic education.

The purpose of this article is to question this received wisdom by looking in detail at the extent to which the RORE patterns reported by GP actually do exist in one major geographical region, namely sub-Saharan Africa (SSA). A close examination of RORE country studies in SSA raises major concerns about, on the hand, the quality and relevance of the ROREs that were originally estimated and, on the other, the reporting and aggregation of these estimates by GP in order to arrive at the now familiar continent-wide ROREs. 
The discussion is structured as follows. The first section assesses the coverage and availability, and the data and methodologies of the RORE country studies used by GP. The second section then goes on to look in detail at the reporting of the individual RORE country estimates and the aggregation process itself, focusing in particular on the comparability of RORE studies in SSA. In the final section, an alternative aggregate RORE pattern for SSA is presented.

\section{RORE COUNTRY STUDIES IN SSA}

Table 2 lists all known RORE studies in SSA by country and author(s), and dates of publication and survey or other data. For the most recent 1993 review, GP presents ROREs by level of education drawn from 18 of these studies. Earlier reviews had used another five (see Tables 3 and 4). After a protracted search process, all but one of these studies (Lesotho) 1 were located and scrutinised.

\section{(a) Country coverage}

The country coverage of RORE studies in SSA is quite limited. The 1993 Review covers just 18 countries (out of 46 in SSA) accounting for approximately half of the total SSA population. $^{2}$ Biases also exist in country coverage. Francophone and Lusophone SSA countries are seriously under-represented while demographically small countries are overrepresented.

Even among the 18 country studies cited by GP, only 11 of them (accounting for $26.5 \%$ of total SSA population) have both private and social RORE estimates for all three levels of education (private, secondary, and higher) for any one year (Botswana, Ethiopia, Ghana, Lesotho, Malawi, Western Nigeria, Senegal, Somalia, Zambia, and Zimbabwe). Another 
complete set of private ROREs by level of education is available for Cote d'Ivoire, and the Burkina Faso and Sierra Leone studies also have complete sets of social ROREs.

\section{(b) Data quality}

In the 1980 Review, GP states that while he would put "least faith" in ROREs where sources of data and estimating techniques "cannot be described in detail", this "does not mean that one has to dismiss these estimates as unreliable" (1980, p.88). He goes on "the criterion here is that a particular author, or journal referee or Ph.D. thesis committee felt that the quality of the work was suitable for publication (in the wider sense and implication of the term)". However, a close examination of the RORE studies in SSA reveals that many of them are of such poor quality that reliance on such a permissive inclusion criterion becomes problematic (see section 2).

In fact, only six out of the 17 publications used in the 1993 Review are theses, ${ }^{3}$ (an M.Phil. covering both Ghana and Western Nigeria), journal articles (Ethiopia, Kenya, Zimbabwe), or books or book chapters (Tanzania, Uganda). The remainder are donor-related reports and discussion papers (5 World Bank, 3 USAID, and 1 ILO) or internal government documents.4 In other words, only a minority of these RORE studies are refereed publications intended for a wider audience. Indeed, the very inaccessibility of what is a very grey literature makes it extremely difficult to assess its quality.

In eight out of the 17 RORE studies that are available for scrutiny (Botswana, Burkina Faso, Ghana, Liberia, Western Nigeria, Sierra Leone, Somalia, Uganda), data limitations are so serious that little confidence can be placed in their ROREs by level of education. All eight are countries with complete sets of social ROREs by level of education so that, at best, there are only five SSA countries with adequate data quality where proper intra-country comparisons of 
ROREs by level of education can be made. In each of the above eight countries, net income benefits by level of education are derived not from formal surveys as is the normal practice but rather on guesstimates made by their authors. GP's own ROREs for Burkina Faso are based on crude information on wages and salaries obtained from an unspecified number of interviews with public and private employers made during the course of a World Bank mission. Similarly, the Ghana, (Western) Nigeria, Sierra Leone, and Uganda studies rely exclusively on public sector salary scales for secondary school and higher education graduates with unsubstantiated assumptions being made about rates of income progression up these salary scales and levels of educational attainment. More serious still, virtually no hard data were available in these three countries on the individual incomes of primary school graduates and those with no education. Their authors had no alternative therefore but to make a series of guesses and assumptions in deriving primary-no education income differentials. 5

The other three country studies (Botswana, Liberia, and Somalia) were undertaken by USAID consultants who merely presented aggregate gross incomes by level of education with no explanation whatsoever about how these were derived. ${ }^{6}$ Not only, therefore, are there serious concerns about the overall quality of the data but also the RORE studies themselves frequently do not provide sufficient information to assess the quality of the data used in their calculations.

Almost all the authors of RORE studies in SSA are fully aware of the serious deficiencies in the incomes data used to estimate ROREs. It is precisely for this reason that they emphasise that the ROREs should only be regarded as "indicative" (Botswana, Liberia, Somalia), "orders of magnitude" (Malawi, Senegal), "rough estimates" (Burkina Faso), "first approximations" based on "negligible data" (Ghana, Nigeria), and "illustrative" (Kenya). Given such poor data, they are understandably cautious in drawing conclusions and, in particular, firm policy recommendations. 7 
What is worrying is that the highly approximate nature of the RORE country estimates in SSA (and probably elsewhere) is obscured in the process of calculating continent-wide aggregate estimates. Given the cautiousness and tentativeness of the original authors, to say nothing about the highly variable quality of data is an important omission. GP does caution the reader not to read too much into one or two percentage point differences in ROREs between countries but such differences pale into insignificance compared to the margins of error in the majority of country studies in SSA.

\section{(c) General methodological concerns}

In his excellent review of education cost-benefit studies in developing countries, Schultz concludes that "most studies build on imperfect specifications and data" (1988, p.586). This is particularly true of RORE studies in SSA. Three basic methodological weaknesses undermine the credibility of most of the ROREs in the 18 country studies under review- sample selection, omitted variables, and reliance on cross-sectional data. 8

\section{(i) Sample selection}

Almost all RORE studies in SSA rely on earnings data from wage employment in the formal sector in order to derive net income benefits by level of education. This is likely to overestimate ROREs for two main reasons. First, and most important, it can be observed in Table 5 that formal sector employment comprises only a relatively small and declining percentage of the total labour force in most SSA countries. Reliance on the formal sector alone would not be so problematic if earnings by educational level are roughly equal to equivalent incomes in the informal and rural sectors. While comprehensive data on rural incomes are not widely 
available in SSA, comparing agricultural value added per rural worker with minimum urban wages (see Table 6) suggests that this was unlikely to be the case in most SSA countries (at least up until the mid 1980s). ${ }^{9}$ Consequently, ROREs for wage employment are likely to be markedly higher than ROREs for self employment. ${ }^{10}$ In particular, because primary school graduates are heavily concentrated in the informal and subsistence agricultural sectors, ROREs for primary education in these sectors are likely to be much lower than in the formal sector. This is borne out in the three country studies in SSA that have adjusted formal sector incomes to take into account lower aggregate incomes in the rural subsistence sectors. Making this adjustment reduces the social RORE for primary education from $14.0 \%$ to $5.0 \%$ in Kenya and from $20.3 \%$ to $14.7 \%$ in Ethiopia (see Thias and Carnoy, 1969 and Hoerr, 1972). In Uganda, the assumption that only $25.0 \%$ of primary school graduates will find wage employment reduces aggregate net income benefits by nearly $50.0 \%$ (see Smyth and Bennett, 1966).

In estimating ROREs in Burkina Faso, GP states that "clearly one cannot make recommendations for the expansion of the education system on evidence pertaining to a mere $1.5 \%$ select group of the labour force (ie. those in private sector wage employment)...The vast majority of primary school graduates will end up being engaged in other activities. The nonwage sector is exactly the place where most of the output of education projects is destined. Yet evidence of the role of education in this sector is lacking up to this point" (1982, p.12). However, the significance of this point is not highlighted in any of the Reviews. Numerous other publications have also used these very partial RORE estimates (based on earnings data for the fortunate minority of the labour force who have jobs) to support major policy recommendations concerning the expansion of primary education as a whole (see, for example, World Bank, 1988). 
In the 1993 review, data are presented that show that global aggregate ROREs for the selfemployed are only fractionally less than the equivalent RORE for those in "dependent" employment. The clear implication here is that excluding the self employed is unlikely to bias seriously country-wide ROREs. But if GP's concerns about the Burkina Faso RORE estimates are anything to go by, he clearly does not believe this to be the case in SSA.

The other major drawback to relying on formal sector earnings is if individual incomes diverge markedly from marginal productivities thereby violating the fundamental human capital assumption upon which ROREs are predicated. The 1985 Review argues that ROREs should be based on "the earnings of those employed in the competitive sector of the economy where the benefits of education better reflect worker's productivity" (1985, p.587). Notwithstanding the above concerns about the inclusion of the self-employed in the informal sector and subsistence agriculture, the problem here is that a distinctly non-competitive public sector occupies a dominant position in the formal sector of most SSA economies. This is particularly the case among skilled occupations where typically over three-quarters of employment is in the public sector. While clearly subject to some competitive pressures from the private sector and, for some occupations, international labour markets, the public sector in SSA wields very considerable monopsonistic market power and is characterised by income determination processes that are as much administrative and political in nature as they are economic. In short, therefore, reliance on public sector earnings is likely to yield RORE estimates that are poor indicators of the underlying social profitability of different types of education investment.

The marked segmentation of the formal sector in SSA between a dominant public sector and an often quite marginal private sector is a reality that the large majority of RORE studies in SSA recognise as deeply problematic. In his own study of ROREs in Burkina Faso, GP argues that "civil service pay scales are not very suitable for social rate of return calculations" (1982, 
p.6) and he opts to use private sector earnings only which at that time were at least $50 \%$ higher than those for equivalent jobs in the public sector. Similarly, in their Tanzanian study, GP and Loxley state that "the structure of earnings in Tanzania is very much a creation of government policy...The private sector is small and a conscious attempt is made to narrow wage differentials in the public sector" (1985, p.221). The RORE estimates for Senegal are based entirely on public sector salaries which Mingat and Jarousse accept is "une limitation importante" (1985, p.52). ${ }^{11}$

Given the dominance of public sector employment along with the absence of private sector earnings data in many studies, the estimates presented for all but a handful of country studies in SSA (Burkina Faso, Cote d'Ivoire, Kenya, Malawi, Zambia, and Zimbabwe) are effectively ROREs to public sector employment with occasional but usually quite minor adjustments for private sector employment. Even with sophisticated general equilibrium analysis for each SSA country, it would be almost impossible to state a priori how the public sector biases ROREs estimates. In the 1980 Review, GP argues that public sector ROREs are likely to underestimate the "true returns to education as judged from private sector employment" (1980:92). But equally, when private sector employment is so marginal as is frequently the case for skilled occupations in the majority of SSA countries (and is itself typically dominated by a small number of companies enjoying considerable market power in both product and labour markets), private sector ROREs may themselves over-estimate the elusive "true" rate of return to education. 12

\section{(ii) Omitted variables}

The provision of formal education is only one of a number of other factors that may independently influence the income determination process among individuals. Omission of these factors can therefore seriously bias ROREs. 
Table 2 lists the adjustment factors that have been included in RORE studies in SSA in order to arrive at adjusted income benefits and costs that more accurately reflect the contribution of formal education. It can be observed that (i) very considerable differences exist among these studies with respect to the treatment of adjustment factors thereby seriously undermining study comparability (see section 2 below); and (ii) only a few studies include all of the key adjustment factors. For the rest therefore, omitted variable bias is likely to be a major problem.

Among the 17 SSA country studies used by GP in the 1993 Review that could be individually scrutinised, eight make no adjustments whatsoever (Botswana, Burkina Faso, Cote d'Ivoire, Malawi, Senegal, Sierra Leone, Somalia, Zambia) and consequently their ROREs are almost certainly biased upwards, probably quite substantially. Another five studies make only a few adjustments for school drop-outs, examination failures, and unemployment (Ghana, Liberia, Western Nigeria, Uganda, Zimbabwe). A further two studies (Ethiopia, Sudan) rely on crudely specified and empirically unsubstantiated and coefficients in order to factor out all variables other than formal schooling that may have independent effects on individual incomes. Only the Kenya and Tanzania studies have separate variables for innate ability and socio-economic background. It is noticeable that ROREs for these two studies are among the lowest in SSA.

Variations in the quality of schooling are also likely to affect RORE estimates. For example, Behrman and Birdsall (1983) found that including schooling quality as an independent variable in earnings functions halved ROREs in Brazil. 13 Significantly, however, none of the RORE studies in SSA cited in the GP Reviews make adjustments for quality of education variables which, again, is likely to result in seriously over-estimated ROREs. More generally, 
this highlights the limitations of earnings function analyses that use 'years of schooling' as the sole school input variable affecting education and labour market outcomes.

Recent research by Glewwe shows that in Ghana it is the quality of existing education provision that is the really critical policy issue in improving rates of return to educational investments. He concludes that, although investments in primary schooling yield "very poor returns" in Ghana, "relatively low rates of return to certain types of education do not necessarily imply that future investments should be directed away from these types, in fact they may indicate that realtively small investments there can have very high returns by raising the rates of return to education" (1991, p.43).

\section{(iii) Cross sectional earnings data}

Full method and Mincerian RORE methodologies ${ }^{14}$ are based on actual or derived ageearnings profiles by level of education for economically active members of the labour force. In calculating ROREs, it has to be assumed therefore that these age-earning profiles remain the same over very long periods of time. Clearly, if earning differentials between education levels do change, as they almost inevitably do, then ROREs will change as well.

Labour market conditions in the formal sectors of African economies have been transformed during the last thirty years or so. Table 5 shows that in the SSA countries included in the 1993 Review, the additional supply of graduates from rapidly expanding education systems (as proxied by total student enrolments) has far outstripped new wage employment opportunities in the formal sector. As a consequence, competition for the few available jobs has become intense. Obtaining better education qualifications than fellow job seekers has been the principal means whereby students with the support of their parents and relations have sought to gain employment. Thus, jobs that were until recently the preserve of primary school 
graduates and illiterates are increasingly being competed for by secondary school leavers as they filter down occupational hierarchies.

GP accepts that "workers with more education qualifications bump from the labour queue those less qualified and get the job" but he argues that "there is nothing wrong with this if the more qualified perform better on the job" (1980, p.92). However, in the SSA context where such massive imbalances exist between the supply of and demand for educated labour (particularly at the primary level), qualification escalation and the related phenomenon of filtering down have become so pronounced and widespread that it seems highly questionable that the benefits of this process of chronic credentialism outweigh its costs. ${ }^{15}$ And, the fact remains that "even with relatively mild forms of screening, even a highly competitive private sector will not yield an efficient allocation of resources" (Klees, 1989, p.259).

Screening and filtering down would be less troublesome if most RORE studies in SSA had been undertaken fairly recently so that, collectively, they provide reasonably accurate and upto-date signals of the social profitability of different kinds of educational investments. In fact, however, of the 18 RORE studies in the 1993 review, 6 are based on data that are over 20 years old (Ethiopia, Ghana, Western Nigeria, Sierra Leone, Sudan and Uganda) and another 9 on data that are more than 10 years old (Botswana, Burkina Faso, Lesotho, Liberia, Kenya, Malawi, Somalia, Tanzania and Zambia). Of all the RORE studies cited in Table 2, in only one country (Ghana) are the data less than five years old (Glewwe, 1991). To derive aggregate ROREs using such old data, in particular in the context of major and worsening mismatches in the supply and demand of educated labour, generalised economic crisis, and since the 1980s, comprehensive economic reform is likely to over-inflate very seriously RORE estimates for all levels of education. In particular, as part of the adjustment process, real incomes (especially in the public sector), plummeted in most SSA countries during the 1980s 
causing sharp contractions in income differentials by occupation and education (see Colclough, 1994).

In all the Reviews, there is a brief discussion about trends in ROREs over time. Comparing aggregate ROREs for developing, intermediate, and advanced countries, GP observes that there is a declining trend in ROREs, but this is "minimal when one considers the large steps in educational expansion" implicit between these three groups of countries (1980, p.95). The possibility that aggregate ROREs may have fallen more dramatically within a continent as a whole is however not considered.

\section{(iv) Cost and benefit biases}

For two main reasons, the derivation of opportunity costs by education level is of central importance in determining the overall level and patterns of ROREs. First, opportunity costs ie. income forgone typically comprise over two-thirds of the total private and social costs of secondary and higher education. And secondly, reliance on standard discounting techniques means that ROREs are largely determined by, and thus highly sensitive to, costs and earnings during the early years of all age-income profiles.

In predominantly rural societies where children make vital, non-marginal contributions to farm and non-farm production, it is incorrect to assume that the opportunity cost of primary education in terms of output forgone is zero or minimal. But, as Table 7 shows, this is precisely the assumption adopted by the majority of RORE studies in SSA for which cost data are available. In Table 8 it can be seen that this failure to account properly for opportunity costs has undoubtedly led to a very serious over-estimation of ROREs to primary education. Even marginal changes in income forgone among primary school graduates (expressed as a percentage of the no-education income for the appropriate age cohort) cause RORE estimates 
to primary education to change dramatically. In aggregate terms, the unadjusted social ROREs for primary education among the seven countries listed in Table 9 with no income forgone for primary education is $97.6 \%$ but this falls to $30.2 \%$ once it is assumed (as GP himself does for Burkina Faso) that income forgone is one-third of no-education income. ${ }^{16}$ It is clear, therefore, that without sound empirical estimates of the output/income forgone by primary school students in SSA, RORE estimates are subject to such enormous margins of error that little confidence can be placed in them. Calculating these opportunity costs of schooling is undoubtedly complex, requiring as it does an in-depth analysis of the activities and labour allocations of representative samples of households in both rural and urban areas. 17

In contrast to primary education, the treatment of opportunity costs for secondary education is uniform in all the SSA studies. Authors take the average earnings from wage employment for the relevant age cohort as the measure of income forgone. These estimates of income forgone for secondary education are much greater than incomes forgone from primary education (see Table 7), which biases strongly ROREs in favour of primary education. However, with such massive job queues in SSA countries, it can be reasonably assumed that the formal sector of the economy forgoes hardly any output/income as a result of secondary school attendance because the size of the pool of unemployed educated youth who are immediately available for work is typically much larger than the number of secondary school students who would be able to find jobs if they were not at school. 18 Thus, the total social opportunity cost of secondary education is no more than the costs incurred by employers in recruiting and training new workers plus any output forgone from self employment. ${ }^{19}$ In SSA, the only realistic alternative to secondary education for the large majority of young people is not wage employment but rather self-employment. Consequently, as with primary school students, it is the output forgone from this type of activity that should form the basis of RORE calculations. 
Turning finally to higher education, none of the RORE studies in SSA include the social benefits that accrue from the replacement of (locally funded) expatriate personnel. When most of these studies were undertaken, foreign professionals, managers and technicians were employed in relatively large numbers in both the public and private sectors. 20 Given the usually substantially higher remuneration costs of expatriate personnel, very sizeable benefits accrue from replacing them with appropriately educated and trained nationals. In Burkina Faso, for example, including these net benefits increases the social ROR to university education from $21.3 \%$ to $71.4 \%$. While not all expatriates are locally funded and their incidence varies markedly from one occupation to another, failure to take them into account can in some countries result in a serious under-estimation of the ROR to higher education. 21 Certainly, the very high cost of expatriates has been a major factor behind Africanisation/localisation programmes in most SSA countries which, in turn, has provided an important justification for the expansion of higher education.

\section{THE AGGREGATION OF RORES}

\section{(a) Country comparsions}

Looking at the RORE estimates for SSA countries as presented in the 1993 Review, it is certainly true that by calculating simple averages of every available RORE for each of the three main levels of education, the now familiar aggregate RORE patterns discussed earlier clearly emerge. However, this process of aggregation masks extremely large variations in ROREs among a relatively small group of countries. For example, the social ROR to primary education in Botswana is four times greater than in nearby Lesotho and the ROR to secondary education in Zimbabwe is nearly ten times greater than in Tanzania. ${ }^{22}$ Furthermore, the 
inclusion of country studies that have incomplete ROREs by level of education in the aggregation process could also bias the findings.

It makes more sense therefore to dispense altogether with simple aggregate ROREs and to look for patterns at the country level. Table 3 shows that of the 12 SSA countries that (according to the 1993 Review) have complete sets of social ROREs by level of education, in only four of them is the RORE to primary education appreciably higher (ie. more than two percentage points) than either secondary or higher education. ${ }^{23}$ It should also be pointed out that the quality of data in all four of these country studies is very poor and two of them (Uganda, Western Nigeria) are based on data from the mid 1960s. Thus, even on the basis of GP's own estimates it is not possible to argue with any confidence that the social RORs to primary education in SSA are that much greater than for other levels of education.

The variability of RORE patterns at the country level in SSA is reflected in the range of education investment priorities recommended by the authors of the RORE studies. Remarkably, only four studies (Ethiopia, Senegal, Sudan and Uganda) argue unequivocally that first priority should be given to primary education. Ten studies (Cote d'Ivoire (1989), Ghana (1969, 1991), Kenya (1969), Malawi (1980, 1984, 1985), Sierra Leone (1975), Zambia (1988), and Zimbabwe (1993)) make recommendations in favour of secondary education and/or have reservations about the social profitability of primary education. The general absence of clear cut statements and recommendations is a direct consequence of each author's lack of confidence in their RORE estimates.

Interestingly, all but two of these nine studies were undertaken by World Bank staff and/or consultants. For example, the 1984 IBRD Report on the Financing and Efficiency of Education in Malawi states that "the social rate of return on investments in secondary education is almost one and half times that of university education and much more than 
primary education, indicating that investment in secondary education is a better investment at this point in time than investments in other sub-sectors (1984, p.45). Even more bluntly, Thias and Carnoy conclude that "an average Kenyan family may not be selecting the best investment when it sends its children to primary school" (1969, p.214). While one may want to question the soundness of this conclusion (especially if the other additional social benefits of primary education are also included), the fact remains that all the Reviews fail to highlight the wide variety of opinions and recommendations expressed by the authors of the individual country studies.

\section{(b) Reporting}

A close examination of the 1993 Review reveals that there are some errors and inconsistencies in the reporting of ROREs studies in SSA. Tables 3 and 4 compare the social and private ROREs presented in the 1993 Review with original study estimates. Discrepancies, some of which are quite striking, exist in seven out of the 23 country studies (Botswana, Kenya (1975), Liberia, Malawi (1980), Senegal, Zambia, and Zimbabwe). ${ }^{24}$

Almost all RORE studies in SSA provide separate estimates for lower and upper secondary education. Both are distinctly separate parts of the education system typically with their own schools and their own terminal qualifications. The non-reporting of ROREs for lower and upper secondary education is therefore an important omission. 25 It can be observed in Table 3 that when ROREs for lower and secondary education are separately ennumerated, the social ROREs to primary education are appreciably higher than any of the other three education levels in only two countries (Liberia, Uganda). 26 Table 3 also presents aggregate ROREs that 
have been recalculated taking into account misreported RORE estimates and with separate RORE series for upper and lower secondary education. These show that the aggregate RORE to upper secondary education is, in fact, the highest and not primary education. However, given all the data and methodology problems of the country studies and the aggregation process itself, this adjusted RORE pattern has no more credibility than that discerned by GP.

\section{(c) Study comparability}

The aggregation of RORE country estimates is only valid so long as all the individual studies utilise the same or very similar methodologies and samples, and rely on data of an acceptable standard. Comparability is, therefore, of paramount importance in any assessment of continent-wide aggregate RORE estimates. Where a choice of RORE studies have been available for any one country, GP has selected for inclusion in the Review "master tables", "the one that in my judgement would be comparable with the rest" (1985, p.585). This is, however, a luxury in SSA since there are only three countries (Kenya, Malawi and Zambia) where more than one RORE study has been undertaken. Consequently, in his up-dating of aggregate ROREs, "faute de mieux, the previous rates of return was retained in countries for which no newer estimates were available" (1980, p.83). What this has meant in practice is that where only one RORE country study is available, it has been included in the master list regardless of its comparability with the other studies.

The following discussion considers in turn three key dimensions of RORE study comparability namely the quality of the research, methodologies employed, and the date of survey data.

\section{(i) The quality of research}


"With one study per country you can show clear effects whereas if you did multiple studies using good quality data sets, as has been done in the USA, you get no clear or consistent results" (Klees, 1989, p.272). This is especially true in SSA where one-off country studies of dubious quality are common. In the absence of other studies, often little more than 'back of envelope' RORE estimates have gone unchallenged and, with the passage of time and sufficient citation, have become established facts.

Of the 17 countries under scrutiny, eight of them can be considered to be of an acceptable academic standard and rely on formal survey data to derive net income benefits by level of education. The remainder, however, are of an unacceptably low standard mainly because individual income data are little more than author guesstimates. Table 9 shows that the aggregate ROREs for the sub-standard group of studies are significantly greater for all levels of education (with the exception of lower secondary), and that among the group of studies that are of an acceptable standard, the ROREs to lower and upper secondary education are appreciably higher than to primary education.

\section{(ii) Methodological diversity}

Quite apart from the general methodological weaknesses discussed earlier, the methodologies actually used in RORE studies in SSA are so dissimilar that they are not comparable for aggregation purposes. Major differences exist with respect to (i) the broad methodological approach adopted; (ii) adjustments for earnings and direct costs; and (iii) adjustments for the opportunity costs of education.

Full, Short-Cut and Mincerian Approaches: Of the three basic RORE methodologies, GP has a definite preference for the full method. Thus, in the 1993 Review, the all important Table A-1 is entitled "Returns to Investment in Education, Full Method, Latest Year". 
However, among the 17 studies available for scrutiny, six of them (including GP's own studies of Burkina Faso and Tanzania) use the short-cut methodology to calculate ROREs. 27 This is important because RORE estimates can diverge significantly between the full and short cut methodologies. 28

GP accepts that the full method and Mincerian RORE methodologies should "in theory at least give very similar results" (1993, p.1), but the 1993 Review makes little use of Mincerian RORE estimates by level of education. For SSA, the one exception is Cote d'Ivoire where private ROREs by level of education that have been derived from standard Mincerian earnings functions are included in the "full method" master table. In total, therefore, well over one-third of the RORE studies used by GP to calculate ROREs by level of education are not based on the full method.

Earnings and Direct Cost Adjustments: RORE studies in SSA also differ markedly with respect to the adjustments that are made to individual incomes and the direct costs of education. These adjustments are of two main types: (i) school drop-out and examination failure rates, and mortality differences and unemployment among individuals with varying levels of education. (ii) Innate ability, work and occupation characteristics, work location, socio-economic background, and economic sector (public-private, formalinformal/subsistence agriculture) that may have effects on individual incomes that are independent of the level of schooling.

Wherever possible, the Reviews have relied upon unadjusted RORE estimates. In the influential 1980 Review, GP significantly downplays the influence of both sets of adjustment factors arguing that they have only a limited impact on RORE estimates. However, wherever data allow, RORE studies do include the above adjustment factors if for no other reason that on a priori grounds it is entirely plausible that they have independent effects on the income 
determination process. Furthermore, in his own research on diversified education in Tanzania, GP does include a wide range of adjustment factors (most notably innate ability, socioeconomic background and location) in calculating ROREs for academic and vocational secondary education.

Reliance on unadjusted ROREs is problematic for two main reasons. First, for at least five of the SSA country studies included in the 1993 Review (Ethiopia, Kenya, Sudan, Tanzania, Uganda) the ROREs presented by GP are, in fact, substantially adjusted. In view of the large differences that typically exist between unadjusted and adjusted ROREs, they are not strictly comparable and should not therefore be included in the same data set for aggregation purposes. Second, and quite apart from the comparability issue, unadjusted ROREs overestimate (often very considerably) the true social and private profitability of investments in education, in particular at the lower levels. With generally higher repetition and failure rates and unemployment among primary school students coupled with relatively low average incomes in the informal/subsistence agriculture sectors, ROREs to primary education that take these factors into account are likely to be lower than unadjusted estimates. 29

Opportunity Costs: Table 7 shows that in nearly half of the RORE studies where data are available, it has been assumed (incorrectly) that the opportunity costs of primary education are zero. Among the remaining studies, opportunity costs are as high as one-third of the average income of no-education workers. As noted earlier, even small changes in the opportunity costs of primary education can have very large impacts on ROREs. This is yet another reason therefore why the (master table) ROREs presented in the 1993 Review are not strictly comparable. Including the true opportunity costs of education would probably reduce significantly ROREs to primary education.

\section{(iii) Temporality}


Temporality is another key issue in RORE studies because of their near universal reliance on cross-sectional incomes data. As has already been discussed, ROREs aggregated by GP are from studies that have been undertaken over a thirty year period. In view of the very significant changes in labour supply and demand conditions in SSA countries that have occurred during this period, any meaningful aggregation process must take the temporal dimension into account.

Two types of evidence are available (but overlooked by GP) that indicate that ROREs in SSA countries have changed appreciably during the last thirty years. First, taking all the 1993 Review estimates for SSA, the aggregate RORE to primary education in countries that rely on pre-1980 data is $29.5 \%$ compared to only $21.4 \%$ for post-1980 data whereas the aggregate RORE to secondary education increases from $14.7 \%$ to $20.5 \%$. If only the country studies with complete sets of social ROREs by level of education are used, then the post-1980 aggregate RORE to secondary education is, in fact, marginally higher than the RORE to primary education (23.5\% compared with $22.1 \%$ ). This is entirely consistent with pervasive job competition, screening, and filtering down in the formal sector.

Second, studies by Knight and Sabot (1987) and Knight, Sabot and Hovey (1992) using good quality data from Kenya have calculated social ROREs to primary and secondary education among "experienced" and "marginal" (ie. relatively less experienced) factory workers. They find that not only are ROREs appreciably lower among more recent cohorts of primary school leavers $(12.0 \%$ compared with an average RORE for all workers of $17 \%)$ but also that the marginal RORE to secondary education is slightly higher than the marginal RORE to primary education (13.0\% and $12.0 \%$ respectively). 30 
More generally, as early as the 1960s, the authors of RORE country studies in SSA were themselves expressing concern about the sustainability of ROREs in the face of the rapid expansion of school enrolments. Thus, in Ghana and Nigeria, "the job expectations of school leavers are having to be lowered every day as each part of the education system expands" (Hinchliffe, 1969, p.16). And in Kenya, Thias and Carnoy conclude that "the rapid decrease in the social rate of return for primary education from 1960 to 1966 suggests that the present volume of primary schooling cannot be justified on economic grounds alone unless delayed income effects or non-economic benefits are taken into account" (1969, p.215).

Failure to take account of what are very sizeable falls in ROREs over time obviously results in the serious over-estimation of current or prospective ROREs, in particular for primary education where labour market effects have been most marked.

\section{CONCLUSION}

Two main conclusions emerge from this examination of aggregate RORE estimates in SSA. First, because the data and methodologies that have been used in individual country studies are deficient and/or incompatible, the aggregate ROREs for SSA presented in the 1993 Review are so flawed that they should be discarded altogether in any serious discussion of education investment priorities both for the continent as a whole and for individual countries.

And second, notwithstanding the shortcomings of the country studies, the conventional RORE patterns almost certainly do not prevail in SSA under current labour market conditions. If any continent-wide RORE patterns are indeed discernible, they are likely to be markedly different. In particuar, it seems highly probable that social ROREs for all levels of education have fallen significantly during the last two decades and in a growing number of 
SSA countries may now be lower than the aggregate social opportunity cost of capital. Furthermore, with chronically low internal and external efficiencies at all education levels in most SSA countries, it seems highly implausible that ROREs in SSA are higher than in the advanced industrial countries.

This does not mean that education is no longer an investment priority for governments and donors. Quite the contrary, well directed and very sizeable investments are urgently needed to raise the quality of education provision. In other words, given the well established (direct and indirect) productivity enhancing effects of education, in particular at the primary and lower secondary levels, potential social ROREs remain as high as ever. But the oft-repeated assertion that public investment in education is relatively attractive because actual social ROREs are relatively high vis-a vis-other types of investment can probably no longer be sustained in many SSA countries, in particular where wage employment opportunities remain minimal and traditional agricultural practices persist.

The noticeable shift of emphasis away from calculating and defending RORE estimates towards the broader societal and individual benefits of education (which are generally excluded in RORE studies) in the policy discourses of the World Bank and other donors in recent years is also indicative of a growing realisation that in the past too much emphasis has been placed on conventional RORE estimates in making the case for education investment. 31

Finally, looking at RORE estimates country by country, it is certainly not the case that the RORE to primary education is consistently higher than either secondary or higher education. Primary education may indeed deserve top priority but it is clear from the foregoing disussion that aggregated ROREs should no longer be relied upon in supporting policy recommendations in the education sector. 


\section{Acknowledgements}

Michael Kelly, Alain Mingat, George Psacharopoulos and Jee-Peng Tan provided invaluable assistance in locating particular RORE studies. Christopher Colclough, Adrian Wood and two anonymous referees made very useful comments on an earlier draft of this paper. The usual disclaimers apply. 


\section{NOTES}

1. The author wrote to GP requesting assistance in locating eight of the RORE studies for SSA. GP was only able to make available his own study of Upper Volta (Burkina Faso). The Ministry of Education in Lesotho conducted its own RORE study in the early 1970s but no longer has a copy of the report (private correspondence).

2. GP incorrectly includes "Rhodesia" as a separate country. This is, in fact, Northern Rhodesia which gained its political independence in 1964 to become Zambia. Also, the "Nigeria" study only covers the Western Region of the country with less than $30 \%$ of the total population.

3. A PhD thesis by Berhanu (1982) is cited by GP as the source for Sudan. These estimates were, however, originally calculated by the ILO/UNDP Employment Mission to Sudan in 1976 (see ILO 1976).

4. All but one of the 17 SSA studies included in the 1993 Review were conducted by foreign economists.

5. In the case of Uganda this guesswork produced an extremely high RORE for primary education of $66.0 \%$ which provides a major fillip to the aggregate RORE for primary education in SSA. Just a few years after the Ugandan study was published, Thias and Carnoy (1969) collected comprehensive high quality income data in neighbouring Kenya using rigorous survey methods and calculated unadjusted ROREs for primary education of around $20 \%$. 
6. It is interesting to note that, as with the Uganda study, the ROREs for primary education in two of these countries (Botswana and Liberia) are exceptionally high. The terms of reference for the three USAID sponsored studies stipulated that ROREs by level of education had to be calculated but that, given time and data limitations, very little importance was attached to these estimates in the overall conclusions and recommendations of each country report.

7. GP himself in his study (with Loxley) of diversified secondary education in Colombia and Tanzania cautions that "it should be emphasised that the usefulness of this calculation (of RORs) lies more in the comparison of curricula than in the absolute levels of returns" (1985, p.203).

8. The problem of measurement error in recording levels of individual school attainment has been widely reported in the literature but it is not specifically mentioned in any of the RORE studies in Africa. Random measurement error with respect to school attainment has been consistently found to bias downwards RORE estimates. For example, a recent study of economic returns to education among monozygotic (identical) twins in the US concluded that between $8-12 \%$ of the measured variance in self-reported schooling levels is error. (See Ashenfelter and Krueger (1994)). If similar measurement errors exist in the RORE studies in SSA, then the true schooling effects on incomes are understated. It is not clear, however, whether there is any differential impact of measurement errors on the pattern of ROREs according to type of schooling.

9. Clearly, for accurate comparisons of urban-rural incomes to be made it is necessary to have data on off-farm incomes as well as farm production.

10. However, because of the importance of income foregone in determining ROREs, it is conceivable that even when incomes from self employment are less than for wage 
employment, ROREs among the self employed could still be higher. A similar argument applies to ROREs for males and females.

11. Mingat and Jarousse do not describe how they have calculated these public sector ROREs. But from the data presented in Annex 4 of their report, it would appear that they have estimated average incomes by level of education, not from survey data but simply from published salary scales and then used the short-cut method to derive ROREs.

12. Another important consideration in relying on public sector salaries is that patterns of public-private sector income differentials vary among occupations within and between countries. For example, earnings data for Burkina Faso presented by GP indicate that at least up until the early 1980s unskilled workers employed in the public sector were paid more than in the private sector but that professionals received a lot less. Nevertheless, in Burkina Faso, reliance on public sector earnings would in fact result in an under-estimation of ROREs for primary and secondary education while the RORE for university education would be seriously over-estimated.

13. For more recent research on the impact of school quality on ROREs, see Behrman et al (1994) and Hanushek et al (1994).

14. ROREs can be derived using one of three basic methodologies. When individual earnings data are available (usually from Labour Force or Household Surveys or Population Censuses) to construct age-earnings profiles for each level of education, the standard internal rates of return equation can be used. The internal rate of return for a particular education or training investment is that rate of return that equalises the present value of expected benefits with the present value of costs or alternatively the rate of interest at which the difference between discounted benefits and costs is zero. 


$$
\sum_{t=0}^{t=n} \frac{B t}{(1+r)^{t}}=\sum_{t=-p}^{t=0} \quad \frac{C^{t}}{(1+r)^{t}}
$$

where $\mathrm{n}$ is the number of years of post-education working life; and $\mathrm{p}$ is the number of years of education.

The short cut method is employed when the only earnings data available are average incomes by level of education. RORs are derived using the following equation:

$\mathrm{r}_{\mathrm{s}}=\mathrm{w}_{\mathrm{s}}-\mathrm{w}_{\mathrm{s}-1} / \mathrm{t}_{\mathrm{s}}\left(\mathrm{c}_{\mathrm{s}}+\mathrm{w}_{\mathrm{s}-1}\right)$

where $r_{s}$ is the rate of return to educational level $s$ over education level $s-1$ as the control group; ws and ws-1 are the mean annual salaries of graduates with $\mathrm{s}$ and s-1 level of education, respectively; $\mathrm{c}$ is the annual cost of per student of educational level $\mathrm{s}$, and ts is the number of years for educational level s. It is argued that this method gives reasonably accurate ROREs when the post-education period is relatively long (at least thirty years) and where the pre- and post-education differentials remain relatively constant over time (see Psacharopoulos, 1982).

The basic Mincerian earnings function method takes the following form.

$\ln \mathrm{y}=\mathrm{b}_{0}+\mathrm{b}_{1} \mathrm{~s}+\mathrm{b}_{2} \mathrm{e}+\mathrm{b}_{3} \mathrm{e}^{2}$

where $\mathrm{y}$ is individual income; $\mathrm{s}$ is years of schooling; and $\mathrm{e}$ is years of work experience.

The extended earnings function method is used to estimate RORs by level of education by converting the continuous years of schooling variable into a series of dummy variables for each educational level. Additional independent variables such as ability, socio-economic background, and work characteristics can also be included in the earnings function.

15. Only two RORE country studies (Ghana and Kenya) have attempted to identify screening effects in a rigorous manner. (Glewwe (1991) and Boissiere, Knight and Sabot (1985)). Neither study is able to establish the existence of a direct, statistically significant realtionship between innate ability (as measured by Raven's Coloured Progressive Matrices) and wages. However, in both studies, innate ability does affect wages indirectly because it enables individuals to acquire more reading and mathematical skills where there are strong, statistically significant relationships with wages. 
16. Assuming zero income forgone in Burkina Faso would have resulted in an embarrassingly high ROR to primary education of $200.0 \%$. Presumably, this is also the reason why the original three digit private RORs for primary education in Botswana (528\%) and Liberia (100\%) were trimmed to $99 \%$ in the 1993 Review.

17. Detailed household analysis may, in fact, show that for some, probably richer households sending children to school can increase household net income/output if by doing so the time of childminders within the household (both adults and/or other children) is liberated for other productive work and the output/income from this released labour exceeds the output forgone from school attendance.

18. It is also the case that in SSA countries such as Kenya and Zimbabwe that have relatively high secondary school enrolment ratios, the minimum educational requirements even for unskilled jobs is completion of lower secondary education so that the (formal sector) income forgone from secondary schooling becomes effectively zero.

19. Of course, for the individual student, he/she does usually forgo some formal sector income by attending secondary school although this has to be adjusted downwards according to the level of unemployment in the relevant youth cohort.

20. This was particularly the case in Francophone African countries. In Cote d'Ivoire, for example, expatriates occupied three-quarters of job positions in the "upper extremes" of the labour force during the mid-1970s. (see Monson, 1979).

21. Even if expatriates are fully funded by aid donors, opportunity costs may still be significant if the resources used to pay their salary costs could be reallocated to other uses.

22. Another obvious concern is that the aggregate ROREs are not weighted by country size. Thus, the ROREs for Botswana with a population of 1.5 million count as much as those for Nigeria with a population of around 90 million.

23. If the social ROREs for Senegal are included then there are five countries where the social RORE to primary education is appreciably higher. However, the social RORE to primary education in Zambia is much lower than secondary education. 
24. The reported ROREs for Ghana and (Western) Nigeria which featured prominently in the 1973 Review are also quite different from the original estimates in Hinchliffe's original 1969 study. In particular, Hinchliffe did not calculate ROREs to primary education. Presumably, the inclusion of these estimates in the 1973 Review was the result of the subsequent collaboration between GP and Hinchliffe. The point to stress however is that the revision and enlargement of the Hinchliffe's original ROREs lacks transparency.

25. Comparing the single "secondary education" RORE Review estimates with the original lower and upper secondary education estimates, there are certain inconsistencies. Specifically, in six countries the RORE for upper secondary has been used, in two countries the lower secondary RORE, and derived aggregate or averaged estimates in another four countries. Similar inconsistencies also arise in the treatment of academic and vocational ROREs for secondary education. In Liberia, these ROREs are simply averaged, in Somalia only the academic RORE is used, and in Tanzania GP relies on a (properly) aggregated estimate derived from original survey data.

26. Separate ROREs for upper secondary education are not presented in the Liberian study. It may well be therefore that ROREs to primary education are only appreciably higher in Uganda.

27. The RORE methodology employed in the three USAID studies in Botswana, Liberia and Somalia is not described but, with only mean incomes by level of education available, the short-cut method would have had to have been used.

28. For example, using the costs and benefits data presented in the the Ethiopia RORE study, the short-cut ROREs are 2.7 times greater than the corresponding full method ROREs for primary education, 2.0 times greater for lower secondary, 1.9 times greater for upper secondary, and 0.33 times greater for university education.

29. The Thias and Carnoy study of ROREs in Kenya is exceptional in that it incorporates comprehensively all key adjustment factors. The unadjusted RORE to primary education is $21.7 \%$ but this falls to just $5.0 \%$ when adjustment factors are included. The corresponding figures for primary education in Ethiopia are $20.3 \%$ and $14.7 \%$ respectively.

30. The data used by Knight and Sabot were collected in 1980. Consequently, it is likely that marginal rates of return on primary education will have fallen still further since then. 
31. The most commonly cited social and demographic externalities relate to education investments are the positive impacts on fertility, the health status of households and the future education of children. (see Schultz, 1988). Another important externality is that schooling increases the capacity of individuals and households to cope with "disequilibria", particularly in relation to technical change. (see Finis (1970) and Schultz (1975)). 


\section{REFERENCES}

Armitage, Jane., and Richard Sabot, "Efficiency and equity implications of subsidies to secondary education in Kenya," in D. Newbery and N. Stern (Eds.), The Theory of Taxation for Developing Countries (Oxford: OUP, 1987), pp.589-614.

Ashenfelter, O. and A. Krueger, "Estimates of the Economic Return to Schooling from a New Sample of Twins," The American Economic Review, Vol. 84, No. 5 (December 1994), pp. 1157-1174.

Baldwin, R.E., Economic Development and Export Growth (Berkeley: University of California Press, 1966)

Behrman, Jere. R. and Nancy Birdsall, "The quality of schooling: quantity alone is misleading," The American Economic Review, No. 73, No. 5 (December 1983), pp. 928-946.

Behrman, Jere R. and Nancy Birdsall, "Comment on "Returns to education: a further international up-date and implications," The Journal of Human Resources, Vol. 22, No. 4 (Fall 1987), pp.603-606.

Behrman, Jere R., David Ross, Richard Sabot and Mattthew Tropp, "Improving the quality versus increasing the quantity of schooling," Mimeo (Philadelphia: University of Pennsylvania, 1994).

Bennell, Paul and Joyce Malaba, "Updating rates of return to education: Zimbabwe in the late 1980s," International Journal of Educational Development, Vol. 13, No. 3 (July 1993), pp. $277-287$.

Berhann, A., "Modelling manpower in development planning: methodological and empirical problems with Sudanese illustrations", Ph.D. dissertation (Pennsylvania: University of Pennsylvania, 1982).

Boissiere, M., J.B. Knight, and R.H. Sabot, "Earnings, schooling, ability, and cognitive skills," The American Economic Review, No. 75, Vol. 5 (December 1985), pp. 1016-30. 
Colclough, Christopher (Ed.), Public Sector Pay and Adjustment: Theory, Policies and Outcomes (Geneva: ILO, 1995)

Cole, Robert E., "Rates of return to education in Zambia," Mimeo (Lusaka: Department of Population, Manpower Planning and Research, National Commission for Development Planning, Government of the Republic of Zambia, 1988).

Fields, G.S. "Higher education and income distribution in a less developed country," Oxford Economic Papers, Vol.27, No. 2,(July 1975), pp. 245-259.

Fields, G.S., "Education and income distribution in developing countries: a review of the literature," in World Bank, Education and Income, Staff Working Paper No 402, (Washington, DC:World Bank, 1980), pp.231-315.

Van der Gaag, T., and W. Vijverberg, "Wage determinants in Côte d'Ivoire: experience, credentials and human capital", Economic Development and Cultural Change, Vol.37, No.2, (January 1989), pp.371-81.

Gebre-ab, N., "Cost-benefit analysis of education in Lesotho," Mimeo (Maseru: Ministry of Education, November 1983).

Glewwe, P. "Schooling, skills and returns to government investment in education: an exploration using data from Ghana," Living Standards Measurement Study Working Paper No. 76 (Washington DC: World Bank, 1991).

Hanushek, Eric. A., Joao Batista Gomes-Neto and Ralph W. Harbison, "Self-financing educational investments: the quality imperative in developing countries," Mimeo (Rochester, NY: University of Rochester, 1994).

Heyneman, S.P., "The evaluation of human capital in Malawi," Staff Working Paper 420 (Washington DC: World Bank, 1980).

Hinchliffe, Keith, "Educational planning techniques for developing countries with special reference to Ghana and Nigeria," MPhil dissertation (Leicester: University of Leicester, 1969). 
Hoerr, O. D., "Educational returns and educational reform in Ethiopia," Eastern Africa Economic Review, Vol. No. (December 1974), pp. 18-34.

ILO, Growth, employment and equity: a comprehensive strategy for the Sudan (Geneva: ILO, 1975).

Klees, S.J., "The economies of education: a slightly more jaundiced view of where we are now', in Francoise Caillods (Ed.), The prospects for educational planning, (Paris: International Institute for Educational Planning, 1989), pp.244-291.

Ketkar, S.L., "Economics of education in Sierra Leone," Discussion Paper, No. 47 (Ann Arbor: University of Michigan Center for Research on Economic Development, April 1975).

Knight, J.B. and R.H. Sabot, "The returns to education: increasing with experience or decreasing with expansion?," The Oxford Bulletin of Economics and Statistics, Vol. 43, No.1, (February, 1981), pp. 51-71.

Knight, J.B. and R.H. Sabot, "The rate of return on educational expansion," Economics of Educational Review, Vol. 6, No. 3, (1987), pp. 255-262.

Knight, J.B., R.H. Sabot, and D.C. Hovey, "Is the rate of return of primary schooling really 26 per cent?," Journal of African Economies, Vol. 1, No. 2 (June 1992), pp.

Komenan, A.G. "Education, experience et salaires en Cote d'Ivoire: une analyse a partir de l'enquete de main d'oeuvre de 1984', Discussion Paper No. 99 (Washington DC: World Bank, Education and Training Department, June 1987).

Mingat, Alain and J-P Jarousse, "L'analyse des couts et du financement de l'education au Senegal," Mimeo, (Dijon: IREDU, July 1985).

Mingat, Alain, Jee-Peng Tan, and Monzurul Hoque, "Recovering the cost of public higher education in LDCs: to what extent are loan schemes an efficient instrument?," Discussion Paper Education and Training Series (Washington DC: World Bank Education Department, 1985). 
Monson, Terry D., "Education returns in the Ivory Coast," The Journal of Developing Areas, Vol. 13, No. 4 (July, 1979), pp. 415-430.

Psacharopoulos, G. (with K. Hinchliffe), Returns to Education: An International Comparison, (San Francisco: Elsevier, Jossey-Bass, 1973).

Psacharopoulos, G., "Returns to education: an updated international comparison," in Education and Income, Staff Working Paper No. 402 (Washington DC:World Bank, 1980), pp.73-110.

Psacharopoulos, G. "Upper Volta: Is it worth spending on education in a "high-cost" country?," Mimeo (Washington DC: Education Department, The World Bank, 1982).

Psacharopoulos, G. "Returns to education: a further international update and implications," Journal of Human Resources, Vol. 20, No. 4, (1985), pp. 583-597.

Psacharopoulos, G., "Education and development: a review," World Bank Research Observer, Vol. 3, No. 1 (January 1988), pp.99-116.

Psacharopoulos, G., "Returns to investment in education: a global update," World Development Vol.22, No.9, (1994), pp.1325-43.

Psacharopoulos, G., and W. Loxley, Diversified Secondary Education and Development: Evidence from Colombia and Tanzania (Baltimore: Johns Hopkins University Press, 1985).

Schultz, T.P., "Education investment and returns," in H. Chenery and T.N. Srinivasan (Eds.), Handbook of Development Economics, Vol. 1 ( New York:North-Holland, 1988), pp.

Schultz, T.W., "The value of the ability to deal with diequilibria," Journal of Economic Literature, Vol. 13, No. 3 (1975), pp.827-846.

Smyth. J.A., and N.L. Bennett, "Rates of return on investment in education: a tool for shortterm educational planning, illustrated with Ugandan data," in The World Yearbook of Education (London: Evans, 1967), pp. 299-322. 
Thias, H.H. and M. Carnoy, "Cost-benefit analysis in education: a case study on Kenya," Report EC-173 (Washington DC: World Bank Economics Department, 1969).

United States Agency For International Development, "Liberia: Education and training sector assessment," Mimeo (Washington DC: USAID, 1983).

United States Agency for International Development, "Botswana: Education and Human Resource Sector Assessment," Mimeo (Washington, DC: USAID, 1984).

United States Agency For International Development, "Somalia: Education and human resources sector assessment," Mimeo (Washington DC: USAID, 1984).

World Bank, African Social Indicators (Washington DC: World Bank, 1993).

World Bank, Financing Education in Developing Countries (Washington DC: World Bank, 1986).

World Bank, Education in Sub-Saharan Africa (Washington: World Bank, 1988). 
Table 1. Aggregate social RORs by level of education and year of GP review.*

\begin{tabular}{|c|c|c|c|c|}
\hline Region & Review Year & Primary & Secondary & Higher \\
\hline \multirow[t]{4}{*}{ AFRICA } & 73 & 28 & 18 & 13 \\
\hline & 80 & 29 & 17 & 12 \\
\hline & 85 & 45 & 26 & 32 \\
\hline & 93 & 24 & 18 & 11 \\
\hline \multirow[t]{4}{*}{ ASIA } & 73 & 14 & 15 & 11 \\
\hline & 80 & 16 & 12 & 11 \\
\hline & 85 & 31 & 15 & 18 \\
\hline & 93 & 20 & 13 & 12 \\
\hline LATIN AMERICA \& & 73 & 33 & 19 & 16 \\
\hline \multirow[t]{3}{*}{ CARIBBEAN } & 80 & 44 & 17 & 18 \\
\hline & 85 & 32 & 23 & 23 \\
\hline & 93 & 18 & 13 & 12 \\
\hline \multirow[t]{4}{*}{ LDC AVERAGE } & 73 & 25 & 17 & 13 \\
\hline & 80 & 27 & 16 & 13 \\
\hline & 85 & NA & NA & NA \\
\hline & 93 & NA & NA & NA \\
\hline \multirow[t]{4}{*}{ ADVANCED AVERAGE } & 73 & NA & 9 & 9 \\
\hline & 81 & NA & 10 & 9 \\
\hline & 85 & NA & 12 & 9 \\
\hline & 93 & 14 & 10 & 9 \\
\hline
\end{tabular}

Source: Psacharopoulos (1973; 1980; 1985 and 1993).

* 1973 figures computed from individual country estimates 
Table 2. ROR studies in Sub-Saharan Africa ${ }^{*}$

\begin{tabular}{|c|c|c|c|c|c|c|}
\hline Country & Study & Year Data & Methodology ${ }^{\top}$ & $\begin{array}{l}\text { Overall } \\
\text { Quality }\end{array}$ & Data & Adjustments ${ }^{+}$ \\
\hline \multicolumn{7}{|l|}{ West Africa } \\
\hline Burkina Faso & Psacharopoulos (1985) & 1982 & $\mathrm{~S}$ & Poor & & None \\
\hline \multirow[t]{3}{*}{ Cote d'Ivoire } & Monson (1979) & 1971 & $\mathrm{~F}$ & Adequate & & DO, FE, FR \\
\hline & Komenan (1987) & 1984 & M & Good & & None \\
\hline & van der Gaag \& Vijverberg (1989) & 1986 & M & Very Good & & $\mathrm{L}, \mathrm{N}, \mathrm{Q}$ \\
\hline \multirow[t]{2}{*}{ Ghana } & Hinchliffe (1989) & 1967 & $\mathrm{~F}$ & Very Poor & & $\mathrm{DO}, \mathrm{FR}, \mathrm{UE}$ \\
\hline & Glewwe (1991) & 1989 & M & Very Good & & A, L, SEB \\
\hline Liberia & USAID (1983) & 1983 & $\mathrm{~S}$ & Very Poor & & $\mathrm{M}, \mathrm{UE}$ \\
\hline Nigeria (Western) & Hinchliffe (1969) & 1966 & $\mathrm{~F}$ & Very Poor & & DO, FR, UE \\
\hline Senegal & Mingat \& Jarousse (1985) & 1985 & $\mathrm{~S} ?$ & Poor & & None \\
\hline Sierra Leone & Ketkar (1975) & 1971 & $\mathrm{~F}$ & Poor & & None \\
\hline \multicolumn{7}{|l|}{ East Africa } \\
\hline Ethiopia & Hoerr (1972) & $1971-72$ & $\mathrm{~F}$ & Adequate & & LFPR, $\alpha(0.5-0.7), \mathrm{S}$ \\
\hline \multirow[t]{6}{*}{ Kenya } & Carnoy \& Thias (1969) & 1966 & $\mathrm{~F}$ & Very Good & & A, DO, FR, FI, L, M, SEB \\
\hline & Fields (1975) & 1971 & $\mathrm{~S}$ & Poor & & None \\
\hline & Armitage \& Sabot (1984) & 1980 & $\mathrm{~F}$ & Very Good & & A, DO, FR, M, SEB \\
\hline & Bossiere, Knight \& Sabot (1985) & 1980 & M & Very Good & & $\mathrm{A}, \mathrm{CA}, \mathrm{SEB}$ \\
\hline & Knight \& Sabot (1987) & 1980 & $\mathrm{~F}$ & Very Good & & $\mathrm{A}, \mathrm{O}, \mathrm{S}$ \\
\hline & Knight, Sabot \& Hovey (1992) & 1980 & $\mathrm{~F}$ & Very Good & & $\mathrm{O}, \mathrm{S}$ \\
\hline Somalia & USAID (1984) & 1983 & $\mathrm{~S}$ & Very Poor & & None \\
\hline Sudan & ILO (1975) & 1974 & $\mathrm{~F}$ & Adequate & & $\alpha(0.66)$ \\
\hline \multirow[t]{2}{*}{ Tanzania } & Psacharopoulos \& Loxley (1985) & 1982 & $\mathrm{~S}$ & Good & & A, SEB, L, S \\
\hline & Knight \& Sabot (1981) & 1971 & M & Very Good & & $\mathrm{O}$ \\
\hline Uganda & Smyth \& Bennett (1967) & 1965 & $\mathrm{~F}$ & Very Poor & & $\mathrm{FR}, \mathrm{SI} / \mathrm{FI}$ \\
\hline \multicolumn{7}{|c|}{ Central and Southern Africa } \\
\hline \multirow[t]{2}{*}{ Botswana } & 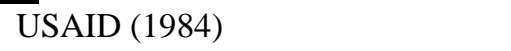 & 1983 & $\mathrm{~S}$ & Very Poor & & None \\
\hline & Hinchliffe (1990) & 1986 & $\mathrm{~F}$ & Adequate & & WE \\
\hline Lesotho & Gebre-ab (1983) & 1980 & NA & NA & & NA \\
\hline \multirow[t]{3}{*}{ Malawi } & Heyneman (1980) & 1978 & $\mathrm{~S}$ & Adequate & & $\alpha(0.90), \mathrm{UE}$ \\
\hline & Tan (1984) & 1983 & $\mathrm{~F}$ & Adequate & & NA \\
\hline & Mingat, Tan \& Hoque (1985) & 1982 & $\mathrm{~F}$ & Good & & None \\
\hline \multirow[t]{2}{*}{ Zambia } & Baldwin (1966) & 1960 & PV & Poor & & None \\
\hline & Cole (1988) & 1983 & $\mathrm{~F}$ & Good & & None \\
\hline Zimbabwe & Bennell \& Malaba (1992) & $1986-87$ & $\mathrm{~F}$ & Good & & UE \\
\hline
\end{tabular}


* RORs for vocational and technical education and training are not included.

$\dagger$ Methodology: $F=$ Full method; $S=$ Short-cut method; $M=$ Mincerian.

$\$$ Adjustment abbreviation: A = ability; $\alpha=$ alpha coefficient; DO = school drop-outs; FR $=$ (examination) failure rates; $\mathrm{L}=$ location; $\mathrm{O}=$ occupation; $\mathrm{SEB}=$ socio-economic background; $\mathrm{M}=$ mortality; $\mathrm{Q}=$ qualifications; $\mathrm{UE}=$ unemployment; $\mathrm{FI}$ = farm income; $\mathrm{SI}=$ subsistence income; $\mathrm{S}=$ sector. 
Table 3. Social rates of return by level of education in Sub-Saharan Africa.*

\begin{tabular}{|c|c|c|c|c|c|c|c|c|}
\hline \multirow{3}{*}{$\begin{array}{l}\text { Country Study \& } \\
\text { Year of Publication }\end{array}$} & \multicolumn{3}{|c|}{ GP 1993 Review } & \multicolumn{5}{|c|}{ Study Estimates } \\
\hline & & & & & & & & Other \\
\hline & $\mathrm{P}$ & $S$ & $\mathrm{H}$ & $\mathrm{P}$ & LS & US & Univ & higher \\
\hline \multicolumn{9}{|l|}{ Complete } \\
\hline Botswana (1984) & 42.0 & 41.0 & 15.0 & 42.0 & 41.0 & 62.0 & 15.0 & 26.0 \\
\hline Burkina Faso (1985) & 20.1 & 14.9 & 21.3 & 20.1 & 18.4 & 5.8 & 21.3 & - \\
\hline Ethiopia (1972) & 20.3 & 18.7 & 9.7 & 20.3 & 28.6 & 18.7 & 9.7 & 14.5 \\
\hline Ghana (1969) & 18.0 & 13.0 & 16.5 & - & 11.5 & 18.0 & 16.5 & - \\
\hline Lesotho (1983) & 10.7 & 18.6 & 10.2 & N/A & N/A & N/A & N/A & N/A \\
\hline Liberia (1983) & 41.0 & 17.0 & 8.0 & 41.0 & $(14.0$ & 20.0) & 8.0 & - \\
\hline Malawi (1986) & 14.7 & 15.2 & 11.5 & $11.1-14.7$ & 21.2 & 15.2 & 11.5 & - \\
\hline Western Nigeria (1969) & 23.0 & 12.8 & 17.0 & - & $11.0-13.0$ & 22.0 & 17.0 & - \\
\hline Sierra Leone (1975) & 20.0 & 22.0 & 9.5 & 20.0 & \multicolumn{2}{|c|}{$(22.0)$} & 9.5 & - \\
\hline Somalia (1983) & 20.6 & 10.4 & 19.9 & 20.6 & $(10.4-$ & 19.7) & 19.9 & - \\
\hline Uganda (1966) & 66.0 & 28.6 & 12.0 & 66.0 & 22.0 & 78.0 & 12.0 & - \\
\hline \multirow[t]{2}{*}{ Zimbabwe (1992) } & 11.2 & 47.6 & -4.3 & (M) 11.3 & 22.8 & 61.5 & 1.9 & - \\
\hline & & & & (F) 11.1 & 26.6 & 33.7 & -4.3 & - \\
\hline Average & 25.6 & 21.7 & 12.2 & 25.6 & $22.4 \uparrow$ & 33.4 & 12.5 & 20.3 \\
\hline \multicolumn{9}{|l|}{ Incomplete } \\
\hline Kenya (1987) & - & 10.0 & & - & 10.0 & - & - & \\
\hline Senegal (1985) & 23.0 & 8.9 & - & 23.0 & 7.7 & 12.0 & 8.9 & 11.5 \\
\hline Sudan (1976) & - & 8.0 & 4.0 & - & - & 8.0 & 4.0 & 7.0 \\
\hline Tanzania (1985) & - & 5.0 & - & - & $1.7-6.3$ & & - & - \\
\hline Zambia (1988) & - & - & 5.7 & $8.0-8.3$ & 37.6 & 47.3 & 5.7 & - \\
\hline Overall Average & 25.4 & 18.3 & 11.2 & 24.2 & 20.5 & 29.9 & 11.2 & 14.8 \\
\hline \multicolumn{9}{|l|}{$\underline{\text { Included In Earlier Surveys }}$} \\
\hline Kenya (1969) & 21.7 & 19.2 & 8.8 & 21.7 & 23.6 & 14.7 & 8.8 & - \\
\hline Kenya (1984) & - & 13.0 & - & - & 9.5-13.0 & - & - & - \\
\hline Malawi (1980) & - & 15.1 & - & - & 21.0 & - & - & - \\
\hline Zambia (1960) & 12.4 & - & - & & & & & \\
\hline
\end{tabular}

* Shading indicates basic reporting error and bold type indicates under-reporting and/or inconsistency in reporting.

$\dagger$ Only where separate LS and US estimates are available have they been included in the average figure. 
Table 4. Private rates of return by level of education in Sub-Saharan Africa.

\begin{tabular}{|c|c|c|c|c|c|c|c|c|}
\hline \multirow{2}{*}{$\begin{array}{l}\text { Country Study \& } \\
\text { Year of Publication }\end{array}$} & \multicolumn{3}{|c|}{ GP 1993 Review } & \multicolumn{5}{|c|}{ Study Estimates (basic) } \\
\hline & $\mathrm{P}$ & $\mathrm{S}$ & $\mathrm{H}$ & $\mathrm{P}$ & $\mathrm{LS}$ & US & Univ & tertiary \\
\hline \multicolumn{9}{|l|}{ Complete } \\
\hline Botswana (1984) & 99.0 & 76.0 & 38.0 & 528.0 & 76.0 & 80.0 & 38.0 & 26.0 \\
\hline Cote d'Ivoire (1987) & 25.7 & 30.7 & 25.1 & 25.7 & 11.3 & 30.7 & 25.1 & - \\
\hline Ethiopia (1972) & 35.0 & 22.8 & 27.4 & 35.0 & 36.7 & 22.8 & 27.4 & 33.4 \\
\hline Ghana $(1969) \dagger$ & 24.5 & 17.0 & 37.0 & - & - & - & - & - \\
\hline Lesotho (1983) & 15.5 & 26.7 & 36.5 & N/A & N/A & N/A & N/A & N/A \\
\hline Liberia (1983) & 99.0 & 30.5 & 17.0 & 100.0 & $(27.0-$ & 34.0) & 17.0 & - \\
\hline Malawi (1986) & 15.7 & 16.8 & 46.6 & $11.6-15.7$ & 26.3 & 16.8 & 46.6 & \\
\hline Western Nigeria $(1969)^{\dagger}$ & 30.0 & 14.0 & 34.0 & - & - & - & - & - \\
\hline Somalia (1983) & 59.9 & 13.0 & 33.2 & 59.9 & $(13.0-$ & 25.1) & 33.2 & - \\
\hline \multirow[t]{2}{*}{ Zimbabwe (1992) } & 16.6 & 48.5 & 5.1 & (M) 15.5 & 25.6 & 59.1 & 6.4 & - \\
\hline & & & & (F) 17.7 & 32.5 & 37.9 & 3.8 & \\
\hline \multicolumn{9}{|l|}{ Incomplete } \\
\hline Kenya (1987) & - & 16.0 & - & - & 16.0 & - & - & - \\
\hline Senegal (1985) & 33.7 & 21.3 & - & 33.7 & 11.1 & 17.3 & 21.3 & 22.4 \\
\hline Sudan (1976) & - & 13.0 & 15.0 & - & - & 13.0 & 15.0 & 12.0 \\
\hline Zambia (1988) & - & - & 19.2 & $7.5-12.1$ & $60.8-65.5$ & $43.6-48.2$ & $19.2-20.5$ & - \\
\hline Included $\quad$ In $\quad$ Earlier & & & & & & & & \\
\hline$\underline{\text { Surveys }}$ & 32.7 & 30.0 & 27.4 & 32.7 & 36.1 & 23.8 & 27.4 & - \\
\hline \multicolumn{9}{|l|}{ Kenya (1969) } \\
\hline Kenya (1975) & 28.0 & 33.0 & 34.0 & - & - & - & 31.0 & 28.0-33.0 \\
\hline Kenya (1984) & - & 14.5 & - & - & 14.5-7.5 & - & - & - \\
\hline
\end{tabular}

* Shading indicates basic reporting error and bold type indicates under-reporting and/or inconsistency in reportin $\dagger$ See note 11. 
Table 5. Supply of and demand for education outputs, selected SSA countries.

\begin{tabular}{|c|c|c|c|c|c|}
\hline Country Study & $\begin{array}{l}\Delta \\
*\end{array}$ & $\begin{array}{l}\text { enrolments } \\
\text { ('000) }\end{array}$ & $\begin{array}{c}\Delta \text { wage } \\
\text { employment } \\
(' 000)\end{array}$ & $\Delta \mathrm{E}: \Delta \mathrm{W}$ & $\begin{array}{c}\text { Wage } \\
\text { employment \% } \\
\text { total labour } \\
\text { force } \dagger\end{array}$ \\
\hline Botswana & & 157 & 122.0 & 1.3 & 50.4 \\
\hline Burkina Faso & & 351 & 35.4 & 9.9 & 3.8 \\
\hline Cote d'Ivoire & & 323 & -7.7 & - & 9.0 \\
\hline Ghana & & 1312 & 80.0 & 16.4 & 3.8 \\
\hline Kenya & & 1709 & 436.0 & 3.9 & 14.1 \\
\hline Lesotho & & 142 & 14.9 & 9.5 & 5.4 \\
\hline Malawi & & 546 & 143.0 & 3.8 & 13.7 \\
\hline Senegal & & 180 & 45.4 & 4.0 & 5.5 \\
\hline Sierra Leone & & 257 & 8.9 & 28.9 & 4.9 \\
\hline Tanzania & & -49 & 9.0 & - & 5.6 \\
\hline Uganda & & 2254 & 13.2 & 17.1 & 4.7 \\
\hline Zambia & & 446 & -4.3 & - & 13.1 \\
\hline Zimbabwe & & 135 & 111.1 & 1.2 & 36.6 \\
\hline
\end{tabular}

Sources: ILO, Yearbook of Labour Statistics; UNESCO, International Yearbook of Statistics; Economist Intelligence Unit, Quarterly Country Reports (various).

* Increases in enrolments and wage employment are between year of original RORE estimates and 1990 (or latest year available).

$\uparrow$ Wage employment covers only employment within national boundaries. 
Table 6. Ratio of minimum wage earnings to agriculture value added per worker, selected SSA countries

\begin{tabular}{lcc}
\hline Country & Year & Ratio \\
\hline Burkina Faso & $(1982)$ & 4.6 \\
Kenya & $(1980)$ & 1.8 \\
Liberia & $(1982)$ & 1.1 \\
Malawi & $(1982)$ & 1.5 \\
Senegal & $(1985)$ & 3.9 \\
Tanzania & $(1982)$ & 1.8 \\
Zambia & $(1983)$ & 3.1 \\
\hline
\end{tabular}

Source: World Bank (1993) 
Table 7. Income forgone by primary and secondary school students, selected countries

\begin{tabular}{lcccc}
\hline & & Income forgone & \multicolumn{2}{c}{ Total income forgone at: } \\
\cline { 3 - 5 } & Currency & $\begin{array}{c}\text { cy primary school } \\
\text { children as \% of no- } \\
\text { education income }\end{array}$ & $\begin{array}{c}\text { primary school } \\
\text { (local currency } \\
\text { units) }\end{array}$ & $\begin{array}{c}\text { lower secondary } \\
\text { school } \\
\text { (local currency units) }\end{array}$ \\
\hline Botswantry & Pula & 0.0 & 0.0 & 2000 \\
Burkina Faso & CFA & 33.3 & 12,650 & 55,000 \\
Cote d'Ivoire & CFA & 33.3 & NA & NA \\
Ethiopia & Birr & 10.3 & 51.5 & 337.5 \\
Kenya (1969) & K£ & 0.0 & 0.0 & 1602 \\
Liberia & US $\$$ & 8.0 & 240 & 3000 \\
Malawi (1985) & Kwacha & $0.0-37.0$ & NA & NA \\
Somalia & So.Sh & 5.8 & 1392 & 20885 \\
Uganda & U $£$ & 0.0 & 0.0 & $90-101$ \\
Zimbabwe & Z $\$$ & 0.0 & 0.0 & 210 \\
\hline
\end{tabular}


Table 8 . RORs to primary education by level of income forgone.*

\begin{tabular}{lllllll}
\hline \multirow{2}{*}{ Country } & \multicolumn{6}{c}{ Income forgone in primary education as \% of no education income } \\
& 0.0 & 5.0 & 10.0 & 20.0 & 33.3 & 50.0 \\
\hline Burkina Faso & 200.0 & 85.4 & 54.3 & 31.4 & 20.1 & 13.8 \\
Liberia & 162.7 & 138.9 & 121.2 & 96.5 & 76.0 & 60.0 \\
Botswana & 56.7 & 50.1 & 44.8 & 37.1 & 30.1 & 24.4 \\
Uganda & 117.0 & 49.0 & 31.0 & 17.9 & 11.4 & 7.9 \\
Ethiopia & 106.7 & 92.1 & 81.0 & 65.3 & 51.2 & 41.2 \\
Somalia & 25.5 & 81.2 & 18.1 & 14.0 & 11.4 & 8.4 \\
Malawi & 14.7 & - & - & - & 11.1 & - \\
Average & 97.6 & 72.8 & 58.4 & 43.7 & 30.2 & 26.0 \\
\hline
\end{tabular}

Source: See Table 8

* These RORs are different from author's own estimates because they have been re-calculated using the short-cut method and are based on unadjusted incomes. 
Table 9. Aggregate social rates of returns by level of education disaggregated by adequate and poor quality data.*

\begin{tabular}{lcccc}
\hline Country Group & $\mathrm{P}$ & LS & US & U \\
\hline Adequate data quality & 15.2 & 23.5 & 25.3 & 6.3 \\
Poor data quality & 31.8 & 17.9 & 27.3 & 15.4 \\
\hline
\end{tabular}

* Country studies with at least adequate data are: Ethiopia, Malawi (1984), Kenya (1969), Zimbabwe, Sudan, Tanzania and Zambia. Those with poor data are: Botswana, Burkina Faso, Ghana, Liberia, Nigeria, Senegal, Somalia and Uganda. 